\title{
Penciptaan Teater "Hikayat Cantoi": Adaptasi dari Konsep Teater Tutur Aceh Adnan PM TOH
}

\section{and THEATREREVIEW}

jurnal tari, teater, dan wayang volume 3 number 1, May 2020 page $26-35$

\author{
Sulaiman Juned ${ }^{1}$ \\ Program Studi Seni Teater, Fakultas Seni Pertunjukan, \\ Institut Seni Indonesia Padangpanjang
}

\begin{abstract}
Creating the monologue theater is based on Teater Tutur Aceh, PM TOH. The author did not start from the saga script but wrote a monologue script entitled "Hikayat Cantoi" and was performed in Indonesian. The show combined the modern convention, especially in movement and blocking of actors on stage, setting (decoration), props, make-up, and clothing by using the wealth of the body as music (body percussion music), such as: pat the chest, thighs, stomach, and fingertips in the Seudati, Didong, and Guel dance. This work presents a character who has historical and psychological complexities. Cantoi, an Acehnese man who works as a teacher, is forced by the situation to become "Pak Turut" to save his soul. The author chose this imaginary character because in Aceh, the term for someone who is smart but looks stupid, and is called Cantoi. Between 1996-2003, Acehnese society experienced a cultural shift or change. It happens because of social interaction through the pressures that are experienced at any time. Changes in social behavior lead to the birth of ideology and the restructuring of people's behavior.
\end{abstract}

Keywords: creative process; monologue; speech theater; Adnan PM TOH; Acehnese locality

\section{Pendahuluan}

Teater sebagai seni yang kompleks mengeksplorasi intensitas seniman dalam bentuk emosi dan spektakel (setiap benda yang ada di atas panggung, termasuk aktor, setting, cahaya, properti, rias dan busana). Menurut Herwanfakhrizal (1996/1997: 10), spektakel adalah ekspresi atau ungkapan sutradara/aktor yang ditangkap oleh penonton dalam wujud struktur dan tekstur serta konvensi sebuah teater menjadi wujud kesatuan tontonan dalam rentang waktu pemanggungannya. Oleh karena itu, sutradara dan aktor harus mampu mengubahlakon verbal menjadi wujud permainan yang mempesona dalam bentuk audio (pendengaran), visual (penglihatan), dan kinetic (gerak). Teater dihidupkan oleh penampilan aktor. Namun, keberadaan para aktor tersebut ditunjang oleh peran sutradara yang membentuk corak dan watak penampilan tersebut.

Naskah lakon merupakan bahan dasar sebuah pementasan dan belum sempurna bentuknya apabila belum dipentaskan. Naskah lakon disebut juga ungkapan pernyataan penulis yang berisi nilai-nilai pengalaman umum, yang juga menjadi ide dasar bagi aktor. Proses pengembangan laku bersumber dari hasil studi dan analisis isi. Hal ini dapat membangkitkan daya kreatif dalam menghayati laku secara pas. Sementara pertunjukan teater tutur Aceh, terdapat PM TOH (mengambil salah satu nama bus yang berada di Aceh). Karena

$\overline{1}$ Alamat korespondensi: Jurusan Teater, Fakultas Seni Pertunjukan ISI Padang Panjang, Jln. Bundo Kanduang, Padang Panjang. Email: sulaimanjuned@gmail.com. 
sering menaiki bus PM TOH untuk bepergian keliling Aceh sebagai penjual obat dan karena kesenangannya dengan klakson bus tersebut, Teungku Adnan selalu mengawali pertunjukan teaternya dengan suara klakson. Teater ini akhirnya diberi nama PM TOH atau juga sering disebut Dangderia, Poh tem atau Peugah haba yang berarti 'berbicara' atau 'orang yang pekerjaannya bercerita'. Sementara itu, naskah lakon yang dimainkan berbentuk hikayat (karya sastra Aceh berbentuk puisi).

Rahman Sabur (2003: 11) mengungkapkan bahwa monolog adalah suatu jenis bentuk seni pertunjukan drama modern yang berasal dari bahasa Yunani. Artinya, suatu pembicaraan atau suatu persoalan dipergelarkan oleh seorang aktor atau sebuah lakon yang berbicara mengenai masalah pribadi seorang tokoh saja. Berangkat dari uraian tersebut, latar belakang tokoh dan cerita monolog tersebut sangat penting bagi setiap pergelaran drama tunggal karena pada umumnya, plot drama senantiasa dipaparkan dengan teknis kilas balik. Hal yang tersaji di awal cerita, pada dasarnya, muncul akibat dari hal yang terakhir dibicarakan tokoh tersebut. Selanjutnya, hal yang sama dilakukan dalam pertunjukan teater tutur Aceh.

Teater tutur Poh Tem, Peugah Haba atau Dangderia yang dipopulerkan Teungku Adnan dengan sebutan PM TOH dimainkan satu orang dalam bentuk monolog. Namun, bila dibandingkan dengan monolog dalam teater modern Indonesia, terlihat beberapa perbedaan. Monolog yang lazim dilakukan teater modern lebih banyak bersifat penuturan dengan melakukan movement (gerak), sedangkan pada teater tutur PM TOH lebih kaya dengan ekspresi, karakter tokoh, dan karakter bahasa dialog yang berubahubah. Begitu juga dengan penggunaan properti, pergantian busana dalam setiap adegan, musik vokal, tubuh, rapa'i dan bantal dimainkan langsung oleh pemeran. Pemeran bermain dengan teknik duduk dan tidak melakukan movement (gerak) atau blocking (perpindahan) dari satu tempat ke tempat yang lain. Teater tutur yang diberi nama PM TOH ini dikembangkan oleh Teungku Adnan dengan mempergunakan alat musik rapa'i Aceh, pedang, suling (flute), bangsi (blockflute), serta mempergunakan properti mainan anakanak dan berbagai macam busana. Properti dan alat musik memperkaya penampilan dan sekaligus menjadi kekuatan dalam mengubah kejadian-kejadian yang diperankan (Sulaiman Juned, 1999: 1-3).

Dalam monolognya, Teungku Adnan bermain sendiri tetapi mampu memunculkan beribu-ribu tokoh. Seolah-olah banyak sekali pemeran yang sedang berperan. Hal tersebut dilakukan lewat kemampuan vokalnya, dan perubahan busana tergantung peran yang dimainkan dalam hikayatnya. Hal tersebut menjadi alasan pemilihan kesenian ini untuk digarap menjadi karya 'perkawinan' teater tutur Aceh dan teater modern Indonesia. Teater tutur ini mempunyai kemungkinan untuk digarap agar keberadaan aktor dalam pertunjukan monolog dapat bersifat menyeluruh sebagai pusat permainan. Monolog memungkinkan aktor hadir sebagai manusia yang absolut. Melalui monolog, aktor dapat menyusun sejarah teater yang lebih memperhitungkan pencapaian keaktoran, baik dalam gagasan teater maupun pencapaian teknik permainan.

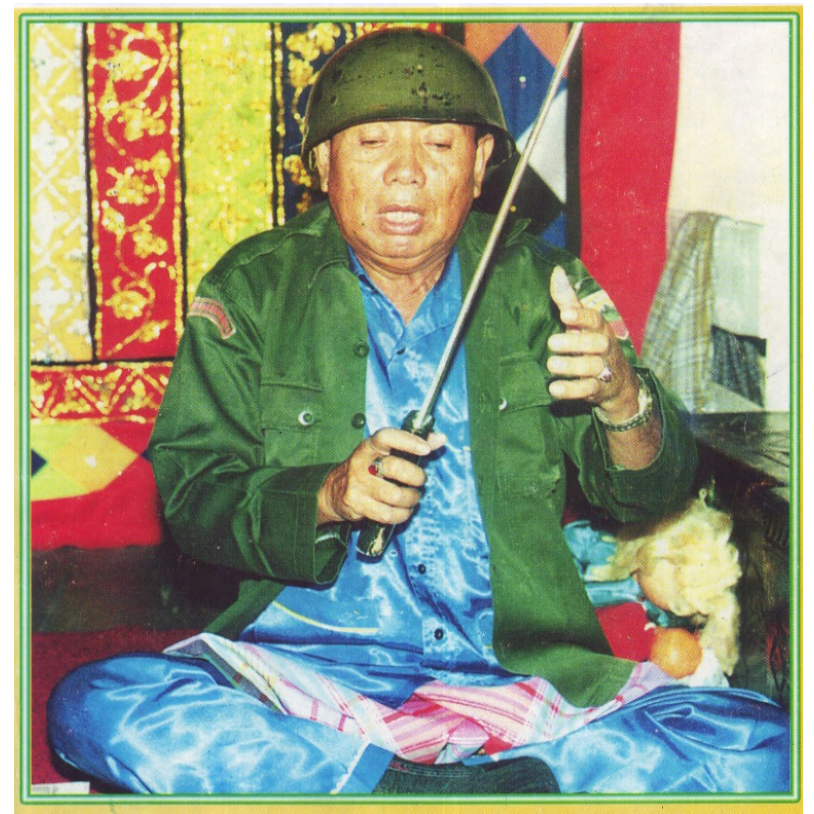

Gambar 1. Teungku Adnan PM TOH, Maestro Teater Tutur Aceh. (Sumber: Sulaiman Juned) 


\section{Pembahasan}

Hikayat dalam bahasa Aceh tidak diartikan seperti makna aslinya, yaitu 'kisah' (cerita). Hikayat bukan hanya berbentuk dongeng duniawi, keagamaan, pelajaran tentang adat, bahkan buku cerita yang ditulis dalam bentuk sajak (puisi), tetapi hikayat ini merupakan hasil sastra yang sangat luas dalam khazanah kesenian Aceh karena dapat menjadi seni pertunjukan" (Budiman Sulaiman, 1988: 10). Hikayat selalu saja terdapat tanda-tanda formal berupa rumus yang memuji Allah serta Rasul-Nya. Jadi teater tutur PM TOH lakonnya selalu saja berangkat dari hikayat, seperti Hikayat Malem Dewa, Malem Dagang, Putroe Ijo, Raja Si Ujud, Prang Sabi, Sanggamara, Nalham Sipheuet Dua Ploh, Gumbak Meueh, dan Indra Budiman.

Teater tutur PM TOH menjadi kebanggaan masyarakat Aceh. Teater tutur tersebut memiliki konsep permainan yang unik sesuai dengan spirit dan nuansa theatrical yang tumbuh dan berkembang di tengah masyarakatnya. Teater tutur ini dimainkan oleh satu orang dalam bentuk monolog. Menurut A.Anjib Hamzah (1984: 411), monolog adalah "Pertunjukan drama yang dilakukan oleh seorang pemain; dialog yang diucapkan pada diri sendiri". Jadi, monolog dikenal sebagai bentuk permainan seorang diri. Seorang aktor harus mampu memainkan peran seorang diri dan memberi bentuk pertunjukan sendiri. Monolog juga biasanya memakai syair dan dialog-dialog yang panjang.

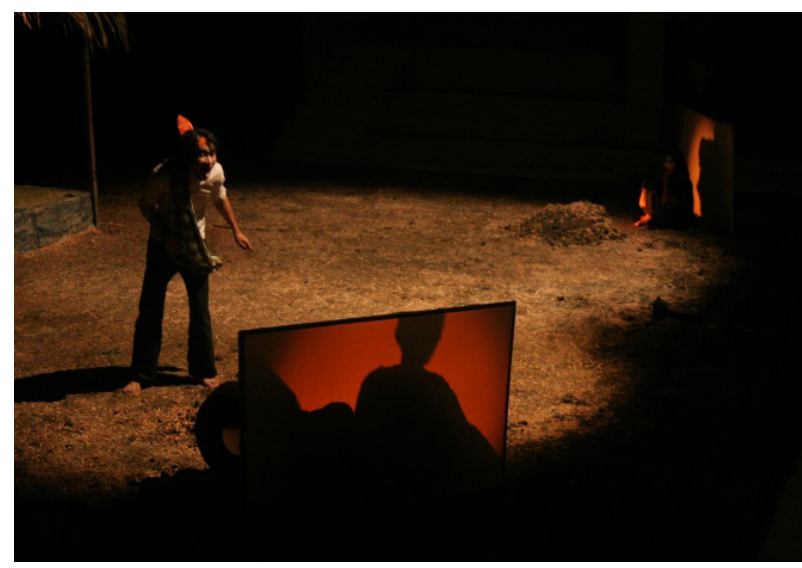

Gambar 2. Pertunjukan Teater berjudul "Hikayat Cantoi” karya/sutradara Sulaiman Juned. (Sumber: Mahruzal)
Menurut Teungku Adnan PM TOH, jauh sebelum teater tutur Poh Tem berkembang, di Aceh Selatan terkenal seorang penyair Dangderia bernama Muhammad Lapei. Mat Lapei menyampaikan hikayat hanya mengutamakan ekspresi wajah, sambil berdiri di atas podium dengan menggunakan pedang pelepah kelapa dan bantal. Sekitar tahun 1956, Teungku Adnan menirukan ekspresi dari Mat Lapei yang selanjutnya menjadi guru Teungku Adnan dalam mempelajari hikayat. Teungku Adnan lalu mengembangkan teater tutur ini dengan memakai kostum yang sesuai dengan tokoh yang ada dalam hikayat, serta menggunakan peralatan, seperti senapan mainan, boneka, pistol-pistolan, wig, topeng dan lain-lain. (Hasil wawancara dengan Teungku Adnan, 14 Desember 2003, di Trienggadeng Pidie, Aceh).

Dasar pemikiran tersebut telah merangsang proses kreatif atas persoalan sosial melalui konsepsi keilmuan dan memunculkan keinginan untuk menggarap teater monolog yang berbasis dari teater tutur Aceh PM TOH. Penulis dalam hal ini tidak berangkat dari naskah hikayat tetapi menuliskan naskah monolog yang berjudul "Hikayat Cantoi" agar dapat dipentaskan dalam bahasa Indonesia. Konsep pertunjukannya mengawinkan konvensi teater modern terutama pada movement (pergerakan), dan blocking (perpindahan) pemeran di atas pentas, setting (dekorasi), properti, rias, dan busana. Selain itu, kekayaan tubuh juga dipakai sebagai musik (musik perkusi tubuh),

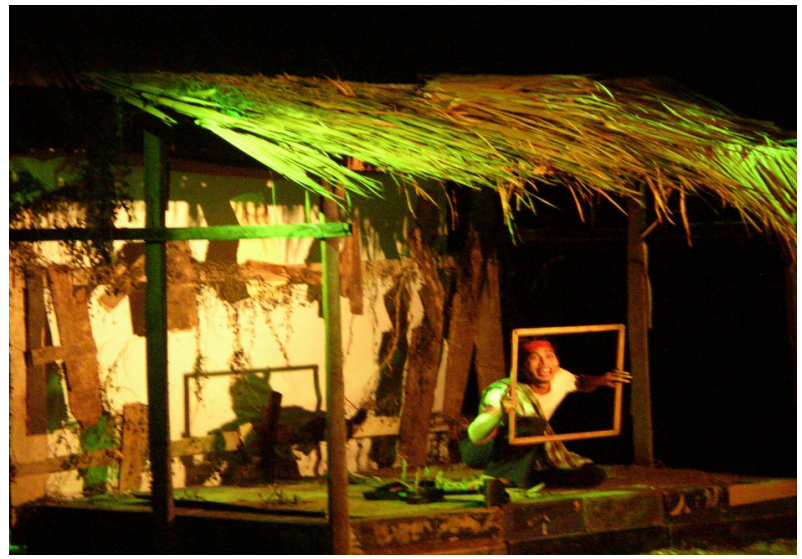


seperti tepuk dada, paha, perut, dan ketip jari (seudati), tepuk tangan (didong), rabana adok, serta gerak tari guel. Seudati merupakan suatu bentuk teater tradisional Aceh yang struktur dasarnya terdapat pada gerak dan syair yang dimainkan seluruhnya oleh laki-laki. Guel sebenarnya bentuk sendratari yang dimainkan oleh beberapa penari wanita dan seorang penari laki-laki dengan gerak patah-patah. Tari ini dilakukan untuk membangunkan gajah jelmaan dari seorang anak raja yang sudah meninggal. Hal itu dipercaya oleh masyarakat Aceh bahwa gajah jelmaan tersebut menjadi gajah putih tunggangan Sultan Iskandar Muda. Sementara itu, didong merupakan teater tradisional Aceh yang kekuatannya terdapat pada syair (cerita yang berbentuk puisi), tepuk tangan, dan goyangan badan yang dilakukan dengan pola duduk melingkar.

Karya ini menghadirkan tokoh yang kompleks secara sejarah dan psikologis. Cantoi, seorang lelaki Aceh yang bekerja sebagai guru, dipaksakan oleh situasi untuk menjadi 'pak turut' agar jiwanya selamat. Lelaki yang berusia 35 tahun ini memiliki seorang istri dan tiga orang anak. Seluruh anak dan istrinya ditemukan tewas di tengah sawah miliknya. Mereka dituduh terlibat dalam Gerakan Aceh Merdeka (GAM). Hal ini membuat Cantoi sangat terpukul, sehingga untuk dapat hidup tenang, ia harus menjadi manusia yang 'pintar-pintar bodoh'. Penulis memilih tokoh imajiner ini karena sebutan di Aceh bagi orang yang sesungguhnya pintar tetapi kelihatannya bodoh dipanggil dengan

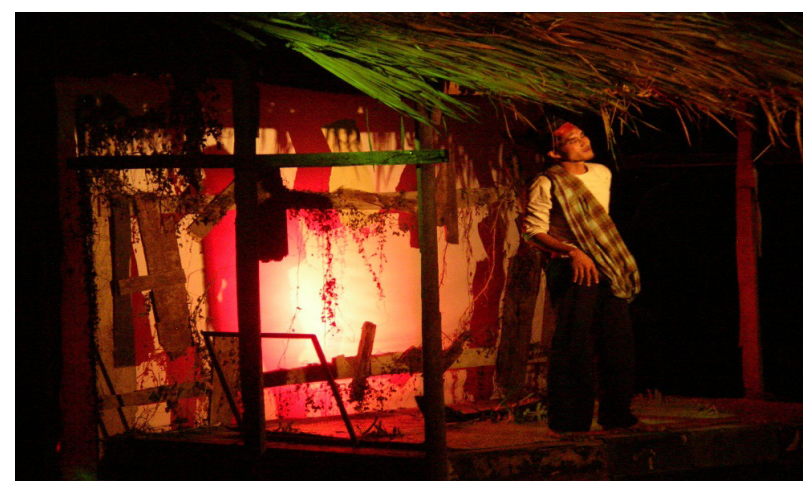

Gambar 3. Pertunjukan Teater berjudul "Hikayat Cantoi" karya/sutradara Sulaiman Juned. (Sumber: Mahruzal) nama Cantoi. Antara tahun 1996-2003, masyarakat Aceh telah mengalami pergeseran atau perubahan budaya. Hal ini terjadi karena interaksi sosial dari hasil kekejaman militer melalui tekanan-tekanan yang dialami setiap waktu. Perubahan tersebut terjadi karena tindak sosial yang menyebabkan lahirnya ideologi dan restrukturisasi terhadap tingkah laku masyarakat.

Interaksi tersebut membuat perilaku normatif masyarakat Aceh saat ini yang terlahir dari kesantunan, rasa persaudaraan, pemurah, peramah, dan setia terhadap siapapun. Namun, interaksi yang terjadi melalui tindakan sosial dengan kekerasan yang dilakukan militer terhadap masyarakat tersebut melahirkan perlawanan tiada henti dari pihak pemberontak. Sementara itu, rakyat tercekam oleh tekanan dan ketakutan karena setiap detik menyaksikan pembunuhan, pemerkosaan, penculikan, pembakaran serta kontak senjata antara Negara Kesatuan Republik Indonesia (NKRI) dengan Gerakan Aceh Merdeka (GAM). Hal ini melahirkan kondisi psikologis, seperti yang dialami tokoh Cantoi, sehingga suatu ketika dia melihat dirinyalah yang mati di lapangan sepak bola itu. Kondisi itu membentuk pemahaman bahwa setiap yang mati pasti dituduh sebagai GAM. Jika bersaudara dengan mereka yang mati tersebut, ia juga harus mati.

Kondisi sosial tersebut menjadi latar belakang lahirnya karya "Hikayat Cantoi" yang berdasar dari realita sosial menjadi media didaktis bagi kehidupan bermasyarakat di Aceh. Jadi, karya ini tidak hanya sebagai media hiburan semata, tetapi juga dapat menjadi alternatif dalam memahami teater monolog sebagai kajian keilmuan dalam idiom teater. Teater yang berdasar dari akar tradisi menjadi sumber penciptaan "Hikayat Cantoi". Dalam hal ini, gerak dasar seudati sangat menarik apabila dapat diterima menjadi blocking (perpindahan) dalam konsepsi pertunjukan teater. Dengan demikian, hal tersebut akan menjadi kebaruan di dunia teater modern Indonesia. Demikian juga kekuatan sastra 
Aceh, baik lewat didong maupun hikayat, dapat menjadi konvensi bagi masa depan teater Indonesia.

Berdasarkan hal itu, penciptaan karya ini mengawinkan konsepsi teater tradisi dengan teater modern untuk memuliakannya. Kondisi di Aceh pada masa konflik menjadi dasar penciptaan teks ke konteks dan menjadi kontekstual. Cantoi merupakan tokoh saksi sejarah atas peristiwayang menimpa Aceh. Dari peristiwa tersebut, banyak anak-anak menjadi yatim, perempuan-perempuan menjadi janda, kampung-kampung dibakar. Peristiwa seperti ini sesungguhnya mencerminkan bahwa penderitaan ditanggung oleh rakyat. Konsepsi teater tutur PM TOH dikawinkan dengan konvensi teater modern pada blocking (perpindahan pemain) aktor, dan movement (gerak) yang tidak dilakukan dalam teater tutur PM TOH. Demikian juga dikonsepkan penggunaan tubuh sebagai musik perkusi, yaitu: tepuk dada, perut, paha, dan tepuk tangan serta ketip jari. Selain itu, ditambahkan penggunaan instrumen musik rabana (adok), musik tekno untuk mengisi efek senjata dan derap sepatu. Dalam hal ini, pemusik juga berfungsi menjadi koor (menjadi rakyat, maling, sekaligus pendekar). Hal ini diperkuat oleh Margaret J. Kartomi (2005) bahwa musik perkusi badan yang ada di Aceh itu sangat luar biasa dan mungkin yang paling maju di dunia, yaitu menimbulkan bunyi musik dengan gesekan tubuh tanpa instrumen.

Setting yang digunakan adalah jambo (pos keamanan). Sementara itu, di sisi kiri depan dan kanan depan dari panggung pentas serta di belakang jambo terdapat kain putih yang berfungsi sebagai layar. Tempat tersebut merupakan tempat duduk para pemusik. Di awal cerita, terdengar lagu "Atjeh Tanoeh Loen Sayang", dan gerakan tari guel yang ditarikan pemusik sambil dilakukan pergerakan dari siluet kiri dan kanan depan pentas menuju ke siluet belakang pentas. Pentas dilanjutkan dengan nyanyian lagu Sebuku. Dalam hal ini, konsep siluet digunakan untuk pencapaian konsepsi artistik sebagai penanda bahwa setiap peristiwa yang terjadi di siluet sesungguhnya pergulatan pikiran dari tokoh Cantoi. Sementara itu, lagu Maju Tak Gentar digunakan untuk menandai munculnya para pendekar. Di akhir cerita (penutup), kembali dinyanyikan "Hikayat Prang Sabi" dan "Atjeh Tanoeh Loen Sayang".

Konsep garapan yang tertuang dari ide dasar naskah monolog "Hikayat Cantoi" menghasilkan akting (laku). Karya ini menampilkan unsur-unsur kebaruan, seperti:

1. Cerita tidak diangkat dari hikayat (kisah/ cerita) seperti "Hikayat Malem Dewa" dan "Malem Budiman". Namun, naskah drama monolog berjudul "Hikayat Cantoi" menuangkan peristiwa yang terjadi di Aceh dalam masa konflik antara Negara Kesatuan Republik Indonesia (NKRI) dengan Gerakan Aceh Merdeka (GAM) di wilayah Aceh. Karya ini bertemakan 'Kekuasaan sangat akrab dengan kejahatan'

2. Bahasa dalam karya ini berfungsi sebagai alat ungkap termasuk gerak tubuh yang merupakan simbol dalam menyampaikan peristiwa. Bahasa yang digunakan dalam pertunjukan adalah bahasa Indonesia. Sementara itu, untuk membangun suasana tertentu dipakai bahasa Aceh, seperti dalam memulai dan mengakhiri pertunjukan dengan memakai nyanyian "Hikayat Prang Sabi" (kisah/cerita perang suci) dan lagu "Atjeh Tanoeh Loen Sayang" serta lagu "Sebuku" (ratapan).

3. Musik dan instrumen yang digunakan dalam karya ini cukup sederhana dengan memakai musik perkusi tubuh serta memakai instrumen rabana (adok) untuk menjelajah kemungkinan bunyi yang ditimbulkan, dan memunculkan suasana-suasana. Selain itu, pemusik yang berperan sekaligus menjadi koor/chorus kadang menjadi tokoh maling, rakyat, dan pedekar.

4. Pertunjukan "Hikayat Cantoi" menggunakan setting jambo (pos keamanan). Di sisi kiri depan dan kanan depan pentas serta di belakang jambo terdapat kain putih yang berfungsi sebagai siluet sekaligus tempat 
duduk para pemusik. Setiap peristiwa yang terjadi di siluet merupakan pergulatan batin dan pikiran dari tokoh Cantoi.

5. Penataan cahaya dalam pertunjukan 'Hikayat Cantoi' sebagai lakon tragedi komedi digarap dengan gaya realisme sugestif (menghadirkan akting, blocking, dekorasi, properti minimalis namun banyak kegunaannya, seperti senjata dapat menjadi pesawat dan cangkul). Seluruh adegan dalam monolog ini terjadi pada malam hari, karena Aceh pada masa konflik oleh penguasa (militer) diberlakukan jam malam. Setiap laki-laki yang ada di kampung-kampung wajib ronda malam agar para pemberontak tidak mudah keluar masuk kampung di waktu malam hari. Warna lampu menentukan suasana yang mendukung tangga dramatic. Warnawarna tersebut adalah biru tua, biru muda, biru, merah, merah hati, merah muda, hijau muda, hijau, kuning, ungu dan merah jambu serta lampu blizt (untuk mendukung suasana peperangan). Melalui peran cahaya, terdapat keinginan untuk memberikan pengaruh psikologis serta menggambarkan suasana pentas dalam lakon. Selain itu, situasi dan kondisi yang terbangun juga dapat menjadi petunjuk waktu.

Proses latihan aktor dalam suatu produksi harus sampai pada bentuk peran yang dicarinya melalui usaha menguasai unsur-unsur seni peran. Atas dasar itu, ketepatan memilih pemain sangat menentukan tingkat keberhasilan pertunjukan. Pentas karya ini juga diawali dengan melakukan pemilihan aktor yang mengutamakan kecerdasan, kecocokan fisik, dan memiliki kejiwaan yang mirip dengan karakteristik tokoh Cantoi agar mampu menerjemakan laku di atas pentas. Terdapat lima orang aktor yang berkenan di casting (pemilihan) menjadi calon tokoh Cantoi, yaitu tiga orang berasal dari Riau, satu orang dari Minangkabau, dan satu orang lagi berasal dari Aceh. Selanjutnya, dilakukan pemilihan dengan cara membaca naskah selama satu bulan. Pembacaan naskah memakai dialek
Aceh. Sementara itu, dialek orang Aceh ketika berbicara dalam bahasa Indonesia sangat sulit ditirukan oleh etnis di luar Aceh. Dengan demikian, diputuskan untuk memilih Azhadi Akbar, mahasiswa Jurusan Teater, Sekolah Tinggi Seni Indonesia (STSI) Padangpanjang (kini ISI Padangpanjang), yang berasal dari Aceh untuk memerankan tokoh Cantoi.

Dalam menentukan karakter tokoh, gaya dikembangkan secara bersama-sama dalam proses latihan. Irama yang tepat menjadi ukuran kecepatan laku dalam pribadi aktor. Hal ini digunakan untuk mengukur kemampuan aktor melakukan pengembangan peran dari proses latihan menuju pertunjukan. Mengenai proses latihan, penulis sebagai sutradara mencoba untuk memakai dua metode, yaitu: latihan di alam bebas dan auditorium. Pelaksanaan latihan di alam bebas dilakukan untuk eksplorasi karakter tokoh. Proses latihan membaca naskah, blocking kasar, penyesuian blocking, latihan mempergunakan properti, seting/dekorasi, busana, cahaya, geladi bersih sampai ke pertunjukan menggunakan gedung Teater Arena Mursal Esten STSI/ ISI Padangpanjang.

Teater sebagai seni yang kompleks harus mampu membahasakan setiap benda yang berada di atas panggung, seperti setting/ dekorasi, properti, rias, cahaya, busana, gerak dan musik. Setting pertunjukan "Hikayat Cantoi" menggunakan jambo (pos keamanan). Di sisi kiri dan kanan depan panggung pentas, serta belakang jambo, terdapat kain putih yang berfungsi sebagai siluet sekaligus tempat duduk para pemusik. Selain itu, digunakan tanah di atas panggung agar tercapai suasana perkampungan, sedangkan untuk properti, digunakan bingkai (penanda jendela), dan senjata yang dapat difungsikan sebagai pesawat dan cangkul. Warna lampu untuk mendukung tangga dramatik adalah biru tua, biru muda, biru, merah hati, merah muda, merah jambu, merah, hijau, dan ungu. Cahaya berpengaruh pada psikologis penonton. Selain itu, cahaya juga dapat menggambarkan suasana pentas selain sebagai penunjuk waktu. 
Tata rias dalam pertunjukan "Hikayat Cantoi" memakai rias karakter (rias efek) khusus untuk tokoh Cantoi, sedangkan untuk pemusik yang berperan sebagai koor digunakan rias gagah dan rias cantik. Busana yang dipakai untuk pertunjukan "Hikayat Cantoi" memakai tipe busana tradisional Aceh. Tokoh Cantoi memakai tengkulok, kupiah hitam, baju putih, celana hitam, dan kain sarung, sedangkan pemusik memakai baju dan celana hitam. Sementara itu, seudati dan guel memiliki gerak magis yang menawan apabila dapat digabungkan dengan kinetic (gerak) yang ada dalam konsep teater modern, maka akan tercipta kebaruan terhadap blocking bagi masa depan teater Indonesia. Penggabungan ini yang dilakukan dalam "Hikayat Cantoi". Pemusik berada di atas pentas menjadi koor yang sekaligus berperan sebagai aktor. Musik perkusi tubuh, seperti; ketip jari, tepuk tangan, tepuk dada, lagu "Hikayat Prang Sabi", "Atjeh Tanoeh Loen Sayang", "Sebuku", didong, dan rabana (adok). Musik tekno hanya untuk mendukung suasana.

Bentuk drama monolog mulai dikenal pada drama-drama Yunani dan Romawi dalam bentuk soliloqui (bentuk monolog yang berdiri sendiri dalam sebuah naskah). Soliloqui merupakan bagian dari adegan naskah yang sedang dimainkan. Pada umumnya, monolog menggunakan syair dan dialog yang panjang. Pelaku merupakan suatu karakter pembicara untuk memperjelas dan menetapkan nama yang sesungguhnya. Pemeran seolah-olah ada dua orang, tiga orang, atau lebih yang dalam pertunjukannya berbicara secara bergantian. Atas dasar itu, deskripsi sajian pertunjukan monolog Hikayat Cantoi sebagai berikut:

1. Dimulai dengan lampu padam. Lalu lampu warna merah di jambo (pos keamanan) hidup, sedangkan tokoh Cantoi tertidur lelap. Kemudian terdengar musik sound effect berupa suara alam, angin, suara tembakan dari senjata, dan suara air gemericik. Suara tersebut diikuti oleh musik perkusi tubuh, ketip jari, tepuk dada, paha, tangan serta musik rabana (adok), sound effect mempergunakan musik tekno, terdengar alunan "Hikayat Prang Sabi" (perang suci) karya Teungku Syik Pante Kulu yang dinyanyikan:

\section{Subhanallah Wahdahu Wabihamdihi}

Khalikul bahri Walaili Azza Wajalla

Uloen pujoe pho sidroe pho syukur keu Rabbi ya Aini

Ke kamoe neubri beusuci Atjeh mulia.

Tajak prang musoh beureuetoh dum sitree Nabi

Nyang meungki keu Rabbi keu pho nyang Esa Meusoe han teuem prang chit malang cilaka tuboh rugoe roeh

Syuruga than roeh rugoe roeh balah neuraka.

Ureueng binoe lah binoe geumoe meukiyam Aneuk jak lam prang peutimang amanah Nabi

Meubek tatakoet taseuroet aneuk senapan bangsawan

Aneuk meuriyam ya Allah ata si Pa'i

Darah nyang hanyi lah hanyi gadoeh di badan

Geuboh lee Tuhan ya Allah ngoen minyeuek kasturi

Dikamoe Atjeh ya Allah darah pejuangpejuang

Neubri beumanyang ya Allah Atjeh mulia.

Terjemahan:

Subhanallah Wahdahu Wabihamdihi

Khalikul bahri Walaili Azza'Wajalla

Segala puji bagi Allah yang Maha Esa

Berikan kepada kami Atjeh Mulia.

Mari kita berperang melawan musuh Nabi Yang melanggar perintah Tuhan Yang Esa Barangsiapa tidak mau berperang di jalan Allah malang untungnya

Orang itu tidak masuk surga tapi malah diberi azab neraka.

Kaum perempuan menangis tersedu-sedu Anaknya berangkat dalam perang menjalankan amanah Nabi

Jangan takut apalagi mundur melihat senjata meriam, bangsawan 
Walau bagaimanapun hebatnya senjata kafir tidak pernah ditakuti.

Bau amis darah akan hilang di badan Kelak diganti dengan wangi kasturi oleh Tuhan dalam surga

Kami bangsa Aceh memang darah pejuang Allah yang meninggikan bangsa Aceh dengan kemuliaan.

2. Lampu warna merah di atas jambo (pos keamanan) hidup remang. Tokoh Cantoi terbangun dari mimpi ketika terdengar'derap sepatu pendekar yang tidak beraturan. Musik perkusi tubuh berupa tepuk dada, paha dan tepuk tangan, ketip jari rebana (adok), dimainkan pemusik yang berada di sisi kiri depan pentas dan kanan depan pentas yang diselubungi siluet dengan lampu warna biru dan merah hati. Terdengar lirik lagu "Atjeh Tanoh Loen Sayang" karya T. Djohan dinyanyikan sebagai berikut:

Daerah Atjeh tanoh loen sayang Nibak teumpat nyan loen hudeueb mate Tanoeh keuneubah endatu monyang Lampoeh deungon blang luah bukhen le.

Keurija hudeueb nasoe peutimang Nasoe peuseunang keurija mate Hate nyang susah loen rasa seunang Atjeh loen sayang sampoe'an mate.

Terjemahan:

Daerah Aceh tanah ku sayang Di sinilah tempat hidup dan matiku Tanah pusaka dari nenek moyang Sawah dan ladang luas sekali

Acara di dalam dunia ada yang mengurusi Masalah kematian ada pula yang menyelesaikannya

Hati yang susah aku rasa senang Aceh kusayangi sampai akhir hayatku.

3. Ketika tokoh Cantoi melakukan tari guel lalu menyanyikan lagu "Sebuku" (ratapan) //...aku harus bagaimana...//. Pemusik juga melakukan gerakan tari guel dan bergerak dari siluet kiri/kanan depan pentas menuju siluet di belakang jambo sekaligus bersebuku di siluet belakang sebagai berikut:

Ee ine bayakku ine

Kusihen aku mungadu

Naseb bangsaku sabe wan karu

Selohen kite moreb wan tenang murenang.

Ee ine bayakku ine

Tentang kupanang-kupanang ari borni seulawah, bayakku

Sek mugersek terides luke masa sedenge kusi kumai Acehku sayang, denang ku denang.

Ho...ho...ho...Acehku sayang denang ku denang

Entimi kite berserulak mukalak ate wan mutalu..иии..иии

Ulak mi kite kumasa sedenge..eee...ee.. bayakku ineee

Keti mujaya Acehku lagu masa silalu..aku harus bagaimana bayakku.

Terjemahan:

Eeee ibuku saudaraku ibuku

Kemana aku mengadu

Nasib bangsaku selalu dalam konflik Kapan kita hidup dalam tenang dan bahagia

Eeee ibuku saudara ibuku

Apabila kusaksikan dari Gunung Seulawah, saudaraku...

Terlihat jelas luka masa lalu

Kemana kubawa Acehku sayang, sambil kunyanyikan

Ho...hoho..Acehku sambil kunyanyikan Janganlah kita melukai hati sendiri dentang berdentang...uuu..

Ingatlah kemasa lalu eeee...eee.. saudaraku ibuku

Agar berjaya Aceh seperti masa lalu...aku harus bagaimana...

Saudaraku ibuku....

4. Cerita ini terangkum dalam struktur dramatik monolog sebagai berikut:

a. Pengenalan, bagian awal dari cerita. Tokoh memperkenalkan siapa sebenarnya Cantoi, maling, pendekar, Cuma 
Habibah, Tgk. Suman, Pak Keuchik, dan Ustadz.

b. Pengembangan, melakukan pengembangan terhadap teks lakon dengan memasukkan unsur-unsur komedi, seperti yang terdapat pada monolog; //Senang jadi Cantoi, cita-citaku tetap Cantoi...dan seterusnya//.

c. Konflikmasalah/peristiwa mengantarkan kepada klimaks sekaligus mendukung munculnya klimaks. Masalah mulai muncul dengan hadirnya tokoh para pendekar untuk mencari maling di Kampung Sabe-Sabe.

d. Klimaks (puncak peristiwa/masalah), ketika pendekar menanyakan kepada penduduk kampung tentang orang yang mungkin mengenal mayat maling yang sudah mati akibat dari kontak senjata dengan para pendekar. Ketika Cantoi melihat mayat tersebut, ia malah melihat dirinyalah orang mati yang dicari identitasnya itu.

e. Konklusi terjadi ketika tokoh Cantoi diseret oleh para pendekar, lampu padam, dan selanjutnya terdengar suara senjata. Jadi, kesimpulan dalam pertunjukan ini diserahkan kepada penonton untuk menafsirkannya.

5. Pemusik muncul di sisi kiri depan pentas dan depan kanan pentas yang ada siluet. Pemusik tersebut sekaligus berfungsi sebagai suara pendekar, Teungku Suman, dan Cuma Habibah dalam bentuk koor. Instrumen musik rebana (adok), dan sound effect yang memakai musik tekno untuk mendukung suasana seram, ketakutan, kesedihan, dan kesakitan serta untuk menghadirkan effek suara senjata.

6. Para pemain melakukan movement (gerak) dan blocking (perpindahan) dengan berdendang (hikayat). Hal ini dilakukan sambil mempersiapkan properti dan hand property, seperti pesawat mainan dan bingkai jendela. Pergerakan ini dilakukan ketika para pendekar baru datang dengan menaiki pesawat, sementara rakyat meng- intip dari jendela rumahnya. Irama lagu "Maju Tak Gentar" terdengar. Tokoh Cantoi dengan memegang cangkul yang dapat berubah menjadi senjata memberi hormat ala militer.

7. Kepala pendekar berpidato di lapangan sepak bola. Hari itu juga terjadi kontak senjata antara para maling dengan para pendekar.

8. Pada saat Cantoi ber-sebuku (meratap) dengan kalimat //......aku harus bagaimana...// lalu bergerak dengan tari guel, pemusik sekaligus melakukan pergerakan dengan tari guel ke siluet belakang jambo.

9. Lampu warna ungu hidup tepat di posisi kiri panggung. Hal ini bertepatan dengan kain putih naik dari bawah ke batem 3 pentas. Kain putih itu simbol dari roh yang terbang kembali ke khalik-Nya. Para perdekar sedang mencari tahu orang yang mengenali mayat tersebut. Seluruh penduduk diam, sebab barangsiapa yang meratapi kematian maling sama dengan bersimpati kepada maling.

10. Cantoi melihat dirinyalah yang mati itu. Bagi masyarakat Aceh, tekanan jiwa seperti ini sering dialami akibat kekejaman militer. Akibat dari ketakutan yang luar biasa karena tekanan tersebut, keberanian itu lahir. Cantoi tidak mau menjawab jati diri orang yang mati tersebut. Cantoi malah berani mengkritisi kekejaman para pendekar, akibatnya Cantoi diseret dan ditangkap oleh para pendekar.

11. Lampu padam. Terdengar musik rebana (adok), serta "Hikayat Prang Sabi" (kisah/ cerita) dinyanyikan kembali. Cantoi terbangun menyanyikan syair sebagai berikut:

Dibuka kelambu tujuh lapis

Cantoi telah dibawa para pendekar

Mungkin dikerangkengkan atau dimatikan Wahai bapak penguji/pembimbing ujian sampai di sini ceritanya.

Kalaulah ada bapak sumur di ladang Bolehlah kita menumpang mandi 
Kalaulah ada umur kita sama-sama panjang

Lain kesempatan disambung lagi.

12. Musik perkusi tubuh berupa ketib jari, tepuk dada, paha, tangan (didong) dan dilanjutkan dengan nyanyian lagu "Atjeh Tanoeh Loen Sayang" serta gerak seudati oleh pemusik di siluet belakang jambo.

\section{Penutup}

Kemampuan Teungku Adnan tidak pernah tergantikan oleh siapapun. Beliau merupakan seorang juru bicara yang memiliki kemampuan untuk "menyihir" penonton karena kemampuannya memberikan pesona seni peran. Pernah dalam "Hikayat Malem Dewa", ia berubah peran dengan sigap. Lima detik pertama, ia mengekspresikan wajah genit, matanya berkedip-kedip. Dia mengenakan sepotong selendang, sebuah wig, dan dia pun menjelma menjadi tokoh Puteri Bungsu, putri yang jelita dari khayangan. Lima detik kemudian, ia berganti peran menjadi pemuda gagah siap bertempur memperebutkan puteri Bungsu. Sepotong pedang terhunus di tangannya sedangakan topi baja melekat di kepalanya. Sementara mulutnya tidak putusputus menderukan kisah pemuda bernama Malem Dewa yang harus berangkat ke negeri di atas awan untuk menemui kekasihnya. Berbagai karakter dengan cepat saling bergantian di tubuh dan suara Teungku Adnan. Ia dapat menjadi Hulubalang, laskar Aceh, jadi nenek penjaga gubuk Buntul Kubu, pemuda yang mencuri baju sang puteri atau seorang anak yang merindukan sang ibu.

Kekuatan yang paling mendasarkan dalam teater tutur PM TOH adalah daya improvisasi penyaji yang sangat tinggi. Gaya komedinya membawakan hikayat masa lalu dikaitkan dengan peristiwa masa kini. Kemampuan Teungku Adnan menyiasati pertunjukan ternyata dapat menghadirkan sejumlah tokoh di atas pentas dengan vokal yang berubahubah. Hal inilah yang menjadi dasar untuk menggarap pertunjukan teater mengawinkan konsep teater modern Indonesia dengan teater tutur PM TOH yang digagas Teungku Adnan sehingga pertunjukan teater 'Hikayat Cantoi' berangkat dari kekayaan lokalitas keAceh-an.

\section{Kepustakaan}

Budiman, Sulaiman. 1988. Kesusastraan Aceh. Banda Aceh: Unsyiah Press

Fakhrizal, Herwan. 1996/1997. "Ekspresi dalam Seni Teater". Jurnal Ekspresi Seni Program Studi Pascasarjana UGM, 1996/1997

Hamzah, A.Adjib. 1984. Pengantar Bermain Drama. CV Rosda Bandung

Juned, Sulaiman. 1999. "Teater Tutur Aceh: Adnan P.M.T.O.H Trobadour yang

Menulis di atas Angin" dalam Jurnal Palanta Padangpanjang: STSI Padang

Kartomi, Margaret J. 2005. dalam Asvi Warman Adam, "Peneliti Musik Aceh Pasca Tsunami”, Harian Kompas Jakarta: 18 Desember 2005

Noor, Agus. 2006. Monolog, Aktor di Panggung Teater. Harian Kompas Jakarta: 26 Maret 2006

Sabur, Rahman. 2003. Pengantar Drama Monolog Enam Tuan Arthur S.Nalan. Bandung: Etno Teater Bandung

\section{Audio/Visual}

VCD. 1998. Hikayat Malem Dewa. Produksi Jurusan Teater STSI Padangpanjang, 